\title{
O ENSINO DE HISTÓRIA E EDUCAÇÃO PATRIMONIAL NA EDUCAÇÃO BÁSICA: Desafios e Possibilidades
}

\author{
Clara Zandomenico Malverdes ${ }^{1}$ \\ Maria Alayde Alcantara Salim²
}

\begin{abstract}
RESUMO
Este artigo tem como objetivo apresentar uma proposta didática no ensino de história nos anos iniciais na educação básica que teve como foco o estudo do conceito de patrimônio a partir da linguagem fotográfica. Inicialmente teceremos algumas reflexões historiográficas relacionadas à ampliação do conceito de fonte histórica e suas implicações no ensino. São apresentados estudos que abordam a relação entre o ensino de história e a educação patrimonial no âmbito dos anos iniciais. O trabalho contou com a participação de 22 alunos de uma turma de 5 ano do Ensino Fundamental de uma escola pública localizada no município de Serra, Espírito Santo. As atividades desenvolveram-se ao longo de um mês, distribuídas em uma aula por semana. Após a análise dos instrumentos produzidos e utilizados, é possível afirmar que a imagem fotográfica apresenta importantes funções comunicativas, e que, no contexto investigado, constatou-se a possibilidade do seu uso como fonte histórica escolar, oferecendo significativa contribuição para a organização do conceito e a compreensão do conteúdo estudado. Palavras-chave: ensino de história; fotografia; educação patrimonial; aprendizagem.
\end{abstract}

\section{TEACHING HISTORY AND HERITAGE EDUCATION IN BASIC EDUCATION: CHALLENGES AND POSSIBILITIES} \begin{abstract}
This article aims to present a didactic proposal in the teaching of history in the early years in basic education that focused on the study of the concept of heritage, from the photographic language. Initially, we will make some historiographical reflections related to the expansion of the concept of historical source and its implications for teaching. Studies are presented that address the relationship between teaching history and heritage education in the context of the early years. The work counted on the participation of 22 students from a class of 5 th grade of elementary school in a public school located in the municipality of Serra, Espírito Santo. The activities were developed over a month, distributed in one class per week. After analyzing the instruments produced and used, it is possible to state that the photographic image has important communicative functions, and that, in the context investigated, the possibility of its use was found. as a historical school source, offering a significant contribution to the organization of the concept and the understanding of the studied content.
\end{abstract}

Keywords: history teaching; photography; heritage education; learning.

Recebido em: $18 / 5 / 2020$

Aceito em: $27 / 7 / 2020$

\footnotetext{
1 Autora correspondente. Secretaria Municipal de Educação - Sedu. Serra/ES, Brasil. http://lattes.cnpq.br/6877313224170531. https:// orcid.org/0000-0002-6658-5940. clara.pedagoga@gmail.com

2 Universidade Federal do Espírito Santo - Ceunes/DECH. São Mateus/ES, Brasil. http://lattes.cnpq.br/7413858625106947. https://orcid. org/0000-0003-4142-9244.
} 


\section{INTRODUÇÃO}

A diversificação das fontes no processo de ensino aprendizagem para crianças dos anos iniciais é uma ação pedagógica imprescindível. A compreensão de conteúdos de forma concreta e visual nessa etapa o torna mais atrativo e estimulante para os alunos. Essa postura, associada aos métodos ativos, abre a possibilidade para que os alunos e os professores ocupem o centro das ações educativas por meio da problematização da realidade compartilhada. Com essa postura investigativa, a construção do conhecimento histórico possibilita o contato com situações concretas, favorecendo o desenvolvimento intelectual dos alunos e rompendo com as práticas pedagógicas de acumulação de fatos apresentados a partir do uso exclusivo do livro didático.

Segundo a pesquisadora inglesa Hilary Cooper (2012), o trabalho com as fontes históricas enseja entre os alunos a conexão entre tempos e lugares diferentes. A respeito das fontes, a autora registra que

Fontes foram criadas com propósitos diferentes e, portanto, possuem diferentes níveis de validade; frequentemente são incompletas. Por isso, os historiadores fazem inferências sobre as fontes, no sentido de saber como foram feitas, usadas e o que podem ter significado para as pessoas que as produziram e as utilizaram (COOPER, 2006, p. 175).

Acreditamos no potencial cognitivo que o uso das fontes históricas representa na relação de ensino aprendizagem no ensino de história. Dessa forma, elas possuem um papel fundamental na produção de um "[...] material didático significativo e facilitador da compreensão de acontecimentos vividos por diferentes sujeitos em diferentes situações [...]". Convém aos alunos ter a percepção de que as fontes e "[...] os registros do passado são os mais diversos e encontram-se por toda a parte: em livros, revistas, quadros, músicas, filmes e fotografias" (BITTENCOURT, 2011, p. 331).

Ainda em se tratando do uso de diversas fontes como recursos necessários ao ensino de história, é importante acrescentar, para o âmbito deste estudo, que, além dos documentos escritos, a fotografia se apresenta como uma fonte bastante interessante. O que propomos em nosso trabalho é a produção da imagem (fotografia) para representar um conceito. Ações como essa visam a possibilitar a democratização do conhecimento, transferindo para as mãos dos educandos o poder de construir seu próprio saber.

Propomos que a fotografia seja usada como fonte histórica ao tratá-la como um fragmento de realidade, uma representação do passado no presente, em que a decisão de registrar certo aspecto foi uma opção do produtor. Durante o processo de leitura da imagem, entretanto, é necessário levantar os diversos aspectos contidos na fotografia e sua contextualização, perceber os conteúdos subjacentes e os motivos para seu registro. $\mathrm{O}$ saber como, por que e para que algumas imagens foram construídas pode alterar todo o seu sentido. Ao descobrir sua autoria, podemos desvendar a visão de mundo do autor, permitindo uma leitura crítica.

O trabalho com imagens no ensino de história no Brasil como recurso pedagógico, marca seu início em meados do século 19, quando, nos livros didáticos de história, aparecem "[...] litogravuras de cenas históricas intercaladas aos textos escritos, além de 
mapas históricos" (BITTENCOURT, 2015, p. 69). Bittentourt (2015) destaca que, o professor Jonathas Serrano, do Colégio Pedro II do Rio de Janeiro, já nas primeiras décadas do século 20, apontava para a importância da imagem como instrumento didático por permitir aos alunos aprender não apenas "pelos ouvidos.

A sociedade do século 20 foi marcada pela disseminação do uso da fotografia como documento de identidade das pessoas, como prova de investigações policiais e de questões jurídicas, além de registros de guerras. A expansão do universo fotográfico provocou uma reviravolta no meio artístico ao propiciar a reprodução do real em situações instantâneas. Como afirma Bittencourt (2011, p. 366): "A fotografia passou a fazer parte do cotidiano e da cultura moderna".

A crescente utilização da fotografia faz com que esta assuma a condição de fonte importante para o estudo da sociedade. Além de transformar-se em objeto de estudo para os cientistas sociais, é apresentada como possibilidade de interpretação do conhecimento histórico, sendo cada vez mais utilizada por historiadores. A partir do final da década de 80, e, especialmente na década de 90 do século 20, ocorre uma ampliação significativa no uso da fotografia em sala de aula, período também fortemente marcado pela "revolução documental" influenciado pelas propostas da História Nova francesa que estavam chegando ao Brasil. Anteriormente a esse período, o ensino de história estaria predominantemente atrelado a uma perspectiva tradicional da história presente nos documentos oficiais e escritos.

\section{O ENSINO DE HISTÓRIA: Fontes e Métodos}

O processo de redemocratização, vivenciado a partir de 1980, ensejou a elaboração de novos programas e novas propostas metodológicas para o ensino de história nas escolas do Ensino Fundamental que refletissem os anseios da população brasileira de que os direitos políticos recém-conquistados fossem acompanhados pela ampliação dos direitos sociais, em especial por uma educação que atendesse às necessidades do novo momento. Fonseca (2006) analisa esse movimento destacando que o processo de mudanças no ensino de história foi iniciado no princípio dos anos de 1980 em alguns Estados brasileiros, como São Paulo e Minas Grais, e que tais projetos educacionais se encontravam articulados a questões relevantes do cenário político e social do país.

Na prática, a efetivação dessas propostas foi um processo longo, marcado, em alguns momentos, pela insatisfação dos professores em relação às diretrizes propostas, fazendo com que estes passassem a elaborarem seus próprios currículos baseados na organização dos conteúdos presentes nos livros didáticos, como também em propostas já produzidas por alguns Estados brasileiros.

Segundo Fonseca (2006), o programa curricular adotado em Minas Gerais atendia às expectativas de um ensino de história democrático e participativo. A adesão por parte dos professores, escolas e algumas famílias a respeito dessa proposta, ocorreu em pouco tempo, resultando numa certa condenação ao modelo tradicional dos conteúdos e metodologias até então considerados fundamentais. A respeito dos conteúdos e práticas de ensino apresentados pela proposta curricular de Minas Gerais, a autora afirma: 
O programa de 1986 pretendia que houvesse uma prática totalmente inovadora e diferenciada por parte dos professores e alunos, por meio de uma mudança de pontos de referência, de visão de processo histórico que, deixando privilegiar os grandes fatos políticos e as grandes personagens da história oficial, partiriam das lutas de classe e das transformações infra-estruturais para explicar a história, revelando, assim, sua clara fundamentação no marxismo (FONSECA, 2006, p. 63).

Os debates travados no processo de elaboração das novas propostas curriculares no final da década de 80 e início dos anos 1990, sem dúvida proporcionaram uma significativa renovação no ensino da história. Essas reflexões ganharam espaço entre os profissionais de história e em organizações, como a Associação Nacional de História (ANPUH), que tinham como uma das propostas a volta das disciplinas de história e geografia e, consequentemente, a extinção dos cursos de Licenciatura curtas em Estudos Sociais.

Os conteúdos e as metodologias sofreram influências em decorrência do debate entre as diversas tendências historiográficas. Questões ligadas à História Social, com novas problemáticas e temáticas de estudo, possibilitaram questionamentos à abordagem tradicional da história, "[...] expondo a influência cada vez mais nítida da chamada 'Nova História', particularmente a tendência de origem francesa" (FONSECA, 2006, p. 66). Segundo Oliveira (2010, p. 44), para os pensadores da Nova História

[...] todos os acontecimentos humanos poderiam ser entendidos como temáticas para a construção da História e não somente a narrativa dos feitos de alguns homens relacionados à história política de seus países. Da mesma forma, toda produção humana seria passível de ser entendida enquanto fonte para a pesquisa do historiador, e não somente os documentos oficiais.

A esse respeito, o historiador Marc Bloch (2001) afirma que nenhum historiador se contentaria, apenas, em identificar quando um fato aconteceu, ou quanto tempo durou, mas busca compreendê-lo em toda sua complexidade e múltiplas correlações. Nesse sentido, amplia-se o conceito de fonte, e novos métodos e técnicas de apoio na pesquisa seriam mobilizados na construção do conhecimento histórico. Por meio de instrumentos como a iconografia, o cinema, a arqueologia, etc., seria possível recriar, reinventar e descobrir múltiplas fontes e novos pontos de apoio na compreensão da história como a "ciência dos homens no tempo" (BLOCH, 2001).

O período denominado a "era do repensar", descrito por Caimi (2001), permitiu, na década de 80 , aos pesquisadores e educadores, novas abordagens e concepções ao trabalhar com a disciplina de história. Considerando a leitura das contribuições trazidas pela Nova História Francesa, a disciplina de história estaria, dessa forma, baseada em questionamentos sobre o passado e o presente, ampliando o conceito de tempo histórico numa dinâmica de longa duração, e privilegiando a preocupação com o homem em seu aspecto social.

No contexto atual das propostas curriculares para o ensino de história encontramos, de forma recorrente, objetivos relacionados à formação de um cidadão crítico, levando o aluno a compreender o tempo presente e se perceber um possível agente de transformação da sua realidade, contribuindo com a formação de uma sociedade 
democrática. Paradoxalmente, os conteúdos para os anos iniciais carregam concepções políticas para a formação de um cidadão disposto a seguir e respeitar as normas do sistema, como assim destacou Bittencourt (2015):

Nas séries iniciais, os conteúdos formulam o ensino das práticas políticas institucionais possíveis, indicando os cargos eletivos dos municípios e estados da Federação, e a divisão dos poderes do Estado. Informam ainda sobre os deveres cívicos dos cidadãos, tais como a necessidade de pagamento de impostos, de prestação de serviço militar e têm sido introduzidos estudos sobre as leis de trânsito, surgindo, assim, as ideias do cidadão-motorista e do cidadão-pedestre e ainda da preservação do meio ambiente, especialmente nas séries iniciais (p. 22).

Dentro dessa perspectiva, a urgência de novas propostas curriculares que modifiquem não só os conteúdos, mas a forma como ensinar história, se justifica como meio de "[...] superar um ensino de História que se fundamenta na construção de um tempo histórico homogêneo [...] e sua lógica de periodização. O que se propõe é [...] trabalhar com diferentes temporalidades e diferentes sujeitos" (BITTENCOURT, 2015, p. 23).

Ao analisar aspectos que configuram o conteúdo escolar, Bittencourt destaca que este se refere tanto aos conteúdos explícitos de cada disciplina como, também, à aquisição de valores, habilidades e competências que fazem parte da prática escolar. Em relação à disciplina de história, Bittencourt (2011) afirma que,

Em História, não se entende como apreensão de conteúdo apenas a capacidade dos alunos em dominar informações e conceitos de determinado período histórico, mas também a capacidade das crianças e jovens em fazer comparações com outras épocas [...] (p. 106).

As discussões travadas no campo da historiografia, aliadas às transformações sociais que marcam a contemporaneidade, tornam insustentável um modelo de ensino de história pautado por diretrizes nacionalistas e constituído por datas cívicas e heróis nacionais. Alicerçados pelos Parâmetros Curriculares Nacionais (2001) e pelas Diretrizes Curriculares Nacionais (BRASIL, 2001, 2013), consideramos importante pensar as políticas públicas voltadas para a organização do ensino e os níveis de aprendizagem, propiciando melhores referências metodológicas e críticas para a seleção e organização dos conhecimentos na formação do aluno.

Dessa forma, a proposta de utilizar novos instrumentos metodológicos capazes de promover o processo de ensino-aprendizagem nos estudos da história, intensificou a importância de diversificar as possibilidades do uso de novas fontes como documentos históricos. Compreendemos, portanto, a urgência em construir uma proposta de ensino identificada com as expectativas e cultura dos alunos, tornando-os sujeitos ativos e pesquisadores de sua história e das questões locais.

\section{A QUESTÃO DA EDUCAÇÃO PATRIMONIAL}

Uma questão fundamental que contribuiu para a utilização do conceito de "Patrimônio" neste estudo surgiu ao detectarmos que os nossos alunos não se reconheciam como sujeitos que constroem a história e, por consequência, não partilhavam da responsabilidade social de valorizar o seu lugar, o seu patrimônio. Nosso movimento 
investigativo partiu da seguinte questão: Como levar reflexões sobre o patrimônio para as aulas de história? E prosseguindo: De que forma os nossos alunos podem construir uma identidade com os patrimônios na medida em que respeitem e se apropriem dos espaços e lugares de memória bem como dos saberes e fazeres da comunidade onde vivem? (PAIM, 2010).

Nesse sentido, o nosso objetivo ao trabalhar com o patrimônio afirma-se na possibilidade de construir um ensino, como reitera Paim (2010, p. 101):

[...] que possibilite aos alunos a compreensão de quem são, a afirmação da sua personalidade, situando-os no espaço, no tempo, na sociedade em que vivem como sujeitos ativos, capazes de compreender, construir e transformar a sociedade.

Assim, é de fundamental importância pensar na constituição dos sujeitos e na sua relação com o mundo, mostrando essa multiplicidade de significações que permeiam o contexto social. $\mathrm{O}$ trabalho com o patrimônio na escola traz essa ideia de legitimidade do sujeito em contextos coletivos e individuais, pois nos faz pensar na pluralidade de significados produzidos em diferentes contextos sociais e que podem se tornar questões importantes de reflexão na representação pela mediação simbólica.

O trabalho com conceitos históricos tornou-se uma prática de reflexão a partir de alguns indícios percebidos por nós professores da educação básica quando, no final do primeiro ciclo do Ensino Fundamental, ao usarmos de dispositivos avaliativos, constatamos que os alunos não possuíam conhecimentos de alguns conceitos básicos imprescindíveis para a formação histórica.

É importante que esteja presente nessa construção um conjunto de ferramentas que possibilite os alunos realizarem uma análise da realidade que os cerca. Nesse sentido, a mediação cultural para a formação dos conceitos históricos é importante para consolidar essa percepção da realidade, posto que ele não é algo "dado" mas construído dentro de um processo dialógico entre os conteúdos históricos, os sujeitos envolvidos e a realidade histórica presente no discurso.

Dessa forma, o diálogo com o patrimônio nos trouxe outra questão relevante que é a contribuição de Vygotsky (2005) com o conceito de cultura. A partir do seu conceito de cultura e mediação simbólica na aprendizagem dos conceitos pelos sujeitos, podemos perceber a importância da cultura nas reflexões sobre patrimônio. Vygostsky (2005) define a cultura como parte que compõe a natureza humana, uma vez que sua característica psicológica está mediada pela internalização dos modos historicamente determinados e culturalmente organizados de operar com as informações.

Sobre as perspectivas de Vygotsky, os sistemas de representação da realidade são socialmente produzidos, especialmente por meio da linguagem. Nesse sentido, a contribuição dada pelo autor apresenta-se no processo cultural como um conjunto de significações mediadas e fornecidas pelo grupo cultural.

Rego (1995) sugere que por esse caminho, mediado pela simbologia, se apresenta o ato de dar significado às coisas, mostrando sua estrutura intrinsecamente dinâmica nas relações sociais. A respeito desse processo de mediação, a autora afirma: 
O pressuposto da mediação é fundamental na perspectiva sócio-histórica justamente porque é através dos instrumentos e signos que os processos de funcionamento psicológico são fornecidos pela cultura. E por isso que Vygotsky confere à linguagem um papel de destaque no processo de pensamentos (REGO, 1995, p. 43).

Pensar pela perspectiva de Vygotsky para entender questões inerentes à cultura, permite-nos compreender melhor a reflexão sobre o conceito de patrimônio, trazendo a importância do reconhecimento de outros sentidos para o patrimônio para além de seu significado tradicional, em razão de diferentes contextos sociais com suas diversas possibilidades de experiências e mediações. Da mesma forma que para Vygotsky (2005) os contextos sociais produzem cultura que são alimentadas pelas possíveis formas de significar o mundo e a si mesmo, o conceito de patrimônio e sua relação com o sentido amplia as diferentes formas de significar o patrimônio nos grupos sociais. Nessa direção, o patrimônio é dinâmico e renovável, pois as formas de compreendê-lo não são estáveis, mas mantêm uma relação de sentido com diferentes contextos e não apenas com o significado.

Tratar a questão do conceito de patrimônio é uma tarefa complexa, pois nos vem, à primeira vista, uma imediata associação da palavra a monumentos e edifícios antigos. Predomina a tendência em considerar o patrimônio histórico, com representações como prédios, monumentos e outras edificações de notável valor histórico-arquitetônico, que, por ser de caráter excepcional, devem ser preservados (ORIÁ, 2015).

Segundo Aroldo Dias Lacerda et al. (2015), as transformações no âmbito do patrimônio no que diz respeito à ampliação da valorização para a noção de imaterialidade, ganham força e se oficializam de fato nos primeiros anos do século 21 , a partir de pressões sociais para o reconhecimento da produção cultural popular que, até então, eram pouco visíveis nas políticas de patrimônio em vigor. Os autores afirmam que existem dois momentos de bastante significância a respeito do patrimônio no Brasil:

Trocando em miúdos, é possível identificar dois momentos, bem definidos, com relação ao que se considera patrimônio cultural no Brasil. Um primeiro, chamado patrimônio de "pedra e cal", de valorização das edificações, e outro momento que se constituiu a partir das últimas décadas do século XX, quando começa a ocorrer uma valorização das manifestações culturais de diferentes grupos sociais. É um momento de incorporação à noção de patrimônio histórico de aspectos processuais da cultura, como saberes e fazeres, componentes da cultura popular brasileira em sua diversidade (LACERDA et al., 2015, p. 13).

Atualmente a expressão "patrimônio histórico artístico" vem sendo substituída por "patrimônio cultural". Essa nova forma de pensar o patrimônio foi expressa na Constituição de 1988, quando amplia o debate em torno na noção de patrimônio cultural.

Com a ampliação do conceito de patrimônio cultural, expresso em nossa Constituição, outras perspectivas para a adoção de uma nova política de proteção ao acervo histórico são desenhadas em nossa sociedade. A possibilidade de construção de uma memória plural torna-se possível a partir do momento em que é incorporado ao sentido de patrimônio a "multiplicidade de identidades que constituem o povo brasileiro e não apenas uma única e homogênea identidade nacional" (PAIM, 2010, p. 94). 
Acreditamos que a atribuição do valor patrimonial a um bem está relacionada à significação de sentidos que este possui para determinado grupo social, justificando, assim, sua preservação. É necessário compreender que os múltiplos bens possuem significados diferentes, dependendo do seu contexto histórico, do tempo e momento em que estejam inseridos. Seus significados variam, também, de acordo com os diferentes grupos econômicos, sociais e culturais, embora, em muitos aspectos, o contexto possa ser o mesmo, pois, conforme afirma Roger Chartier (2002, p. 24), "todo receptor é, na verdade, um produtor de sentido, e toda leitura é um ato de apropriação".

A partir de experiências que temos vivenciado no trabalho com a educação patrimonial, partilhamos de diversas propostas educativas por meio da investigação, da reflexão e da criação do conhecimento produzido na escola. Dentro dessas possibilidades de trabalho, encontramos na fotografia uma forma de promover atitudes e competências com o objetivo de levar os alunos a desenvolverem atitudes reflexivas, críticas e comprometidas com o ambiente em que vivem. Dessa forma, a fotografia constituiu-se em um meio para a ampliação da percepção estética e criativa sobre os lugares, as paisagens sociais, arquitetônicas, naturais e culturais exploradas. Para tanto, diversas ações educativas e integradoras privilegiaram temas vinculados à realidade sociocultural brasileira, caracterizada pela dinâmica da pluralidade nas suas elaborações e reelaborações.

A proposta de utilização da linguagem fotográfica apresenta-se como um recurso pedagógico privilegiado para o desenvolvimento do raciocínio concreto, da observação, da reflexão e da capacidade estética e criativa dos nossos alunos. A prática da observação e percepção que procuramos realizar por meio de visitas orientadas ${ }^{3}$ a pontos históricos de Serra, município do Espírito Santo, quando os alunos produziram fotos com câmeras amadoras, permitiu o registro do conteúdo estético e criativo, documentando o tangível e o intangível presentes na sociedade serrana.

Nossa perspectiva com essa ação educativa é desenvolver uma possibilidade pedagógica de apropriação cidadã por parte de alunos em situação de desvantagem social do espaço em que habitam, construindo relações de identidade entre o conhecido e o vivido, reelaborando valores e atitudes que vão ao encontro dos princípios de valorização, preservação da vida na sua complexidade e simplicidade de forma crítica e criativa.

Atividades que visem a proporcionar aos alunos o contato com lugares diversos e formas de preservação de memórias, como museus, arquivos, centro de memórias, entre outros, são fundamentais para que utilizem esses espaços de maneira plena e apropriada. Nesse sentido, o estudo do meio também pode ser uma boa opção de intervenção pedagógica no trabalho com a educação patrimonial. As informações presentes no cotidiano tornam-se preciosos instrumentos de coleta de dados, registro de informações e capacidade de observação, favorecendo o desenvolvimento intelectual

\footnotetext{
As visitas orientadas com o fim pedagógico proporcionam unir o aprendizado ao lúdico. Com isso, os alunos vão conhecer novos lugares, conhecer novas culturas, aceitar as diferenças do próprio grupo e do lugar visitado, ter responsabilidades, flexibilidade, lidar com possíveis situações inusitadas e divertirem-se, fatores que vão preparálos para a vida adulta.
} 
dos alunos. As possibilidades de trabalho com documentos será o ponto de partida para a utilização da fotografia como uma das alternativas de evidenciarmos o conhecimento sobre o patrimônio.

A articulação da história com a fotografia teve como objetivo ampliar as possibilidades de produzir conhecimentos históricos, artísticos, técnicos, culturais, de forma envolvente e prazerosa, favorecendo o processo de produção de conhecimentos relacionados à cidade de Serra e à vida de cada um na cidade. A intenção, portanto, de uma educação patrimonial significativa, é promover, dessa forma, a aproximação dos alunos à sua realidade, estabelecendo um diálogo permanente com a sua história, a sua cidade, o seu patrimônio artístico cultural e ambiente natural, ou seja, com a sua identidade.

Apesar das precárias condições da maioria das nossas escolas públicas na atualidade, produzir conhecimento é saber ser criativo e autônomo, procurando, da melhor maneira possível, tornar a realidade escolar um espaço privilegiado de trocas e experiências.

Lançamos, então, o desafio para que possamos garantir e reforçar um sentimento do patrimônio para a valorização das memórias dos sujeitos comuns, pois, como diz o velho ditado: "[...] Ninguém ama aquilo que não conhece" (PAIM, 2010, p. 102). Quem sabe, assim, possamos, daqui a algum tempo, ouvir de muitos professores que os alunos gostam das aulas de história, e querem conhecer cada vez mais histórias, e como sentem orgulho das memórias de seu grupo.

\section{MÉTODO E INSTRUMENTOS METODOLÓGICOS}

A construção da metodologia com a utilização de conceitos-fotos teve por objetivo propiciar aos alunos uma experiência com o tempo. Assim, a pesquisa foi conduzida por três eixos centrais: a participação do aluno em colaboração no desenvolvimento de sua aprendizagem de forma individual e coletiva; o uso das tecnologias na captação da imagem, permitindo um trabalho pedagógico com os conteúdos de um modo mais rápido e eficaz; e, por fim, um método diferenciado que possibilite uma aprendizagem significativa produzindo motivação e interação entre os sujeitos.

O nosso trabalho baseou-se no método de pesquisa participante e foi realizado a partir do trabalho colaborativo entre o pesquisador, o professor regente da turma e os alunos. Foram utilizados instrumentos como questionários, grupos de discussão, entrevistas e observação como técnica de coleta de dados. Nosso campo de pesquisa foi a Escola de Ensino Fundamental Irmã Cleusa Carolina Rody Coelho, localizada no Bairro Cidade Continental, no município de Serra, região metropolitana da Grande Vitória-ES. A turma selecionada para o desenvolvimento da pesquisa foi o 5 o ano $B$ do turno matutino, composta por 22 alunos.

A escolha por essa escola se deu a partir de vivências das pesquisadoras, bem como por possuir os dois níveis de escolarização, ou seja, a escola conta com turmas do 10 ao 9o anos do Ensino Fundamental. O recorte da turma justifica-se por se tratar de uma fase de transição importante do Ensino Fundamental I para o Ensino Fundamental II e por meio de intervenções nas formações continuadas na escola. Percebermos, por meio das falas dos professores, que muitos alunos carregavam para a fase final do 
Ensino Fundamental algumas dificuldades, por exemplo, na apropriação de conceitos e seu uso em outras situações, ou seja, uma apreensão da história muito estanque, sem mobilizar os conceitos para a compreensão histórica.

No desenvolvimento da pesquisa de campo foi utilizada uma metodologia intitulada Imaginando, desenvolvida por uma equipe da Universidad Complutense de Madrid, com coordenação dos professores Juán Miguel Sánchez Vigil, Maria Oliveira Zaldua, Antonia Salvador Benítez e Frederico Ayala Sorenssen. Consiste na utilização de imagens produzidas por alunos para representar diversos conceitos trabalhados em sala de aula, com o intuito de elaborar um conhecimento individual e compreender o conteúdo proposto (VIGIL, 2012).

O referido projeto traz como proposta a participação do aluno como protagonista na construção do seu próprio conhecimento, colaborando com a aprendizagem do coletivo. A ideia, portanto, é que, a partir da produção da imagem por meio da captação do seu olhar individual e da fotografia, o aluno possa desenvolver habilidades enriquecedoras na compreensão e assimilação a respeito de determinados conteúdos trabaIhados e, com essa ação, seja capaz de analisar criticamente o que foi elaborado por ele individualmente e em colaboração com o conhecimento produzido em grupo.

A metodologia Imaginando permite um processo de compreensão dos conceitos trabalhados na medida em que representar uma definição em uma imagem exige o entendimento por completo do conceito a ser retratado, compondo-se de cinco passos:

(i) discussão teórica com os alunos, embasada em bibliografia especializada, para atingir um nível comum de compreensão conceitual de termos específicos; (ii) produção de imagens inéditas - e/ou reaproveitamento de imagens anteriores feitas pelos próprios participantes -, representativas de tais ideias e/ou conceitos; (iii) consolidação dos conceitos mediante discussão das imagens realizadas por todos (alunos e professores) em sala de aula; (iv) ajustes nas imagens ou produção de novas em função de tal debate; (v) elaboração de ficha descritiva e texto explicativo sobre cada imagem final, com vistas à documentação, criando um banco de imagens de uso não-comercial. O ciclo pode, a partir daí, ser reiniciado com outras temáticas e conceitos (LOPEZ et al., 2013, p. 204).

Nessa perspectiva, a metodologia Imaginando propicia a compreensão dos conceitos trabalhados na medida em que o processo de representar uma definição por meio de uma imagem pressupõe um movimento de aproximação e entendimento em relação ao conceito a ser retratado.

Durante nosso percurso como professores de história dos anos iniciais, nos sentíamos instigados em compreender como era possível que crianças que nasceram no município de Serra não se reconhecem como parte integrante da história local. A maioria dos alunos não tinha sequer noção da história de seu município e nunca havia feito uso social de bens culturais preservados, como o patrimônio arquitetônico da cidade, por exemplo.

O trabalho envolvendo questões relacionadas ao Patrimônio Cultural vem, dessa forma, reformular esse conceito, pois prevaleceu durante décadas no Brasil uma ideia vinculada ao patrimônio como sendo somente espaços de "Pedra e Cal" (BITTENCOURT, 
2015). Essa concepção restrita de patrimônio cultural abrangia apenas a importância histórica a sítios arquitetônicos, edificações, monumentos e construções, desconsiderando, desse modo, a dimensão imaterial do patrimônio.

Para além de manifestações por meio de objetos, edificações e monumentos, uma ampliação conceitual na percepção de Patrimônio Histórico Cultural ganha força na defesa da preservação e valorização da memória coletiva na qual Pierre Nora definiu como "a memória, ou o conjunto de memórias, mais ou menos conscientes de uma experiência vivida ou mitificada por uma comunidade, cuja identidade é parte integrante do sentimento do passado" (NORA, 1978, p. 398).

A ampliação do conceito de patrimônio levou à criação de um novo instrumento de preservação estabelecido pelo Decreto $n=3.551 / 2000$. Consta, nesse decreto, a ampliação para a esfera imaterial do patrimônio, ou seja, conhecimentos e modos de fazer enraizados no cotidiano das comunidades, bem como as celebrações religiosas e a vivência coletiva do trabalho que marcam as práticas da vida social, e também iriam compor o registro de bens culturais considerados patrimônio.

Teremos como foco principal a utilização de pressupostos e princípios da educação patrimonial a partir do uso da fotografia como ferramenta metodológica, documento e fonte histórica escolar. Dessa forma, considerando as etapas de aplicação/análise da metodologia Imaginando e dos demais instrumentos de coleta de dados, analisamos a produção fotográfica e as fichas descritivas realizadas pelos alunos a fim de verificar quais foram as dificuldades e as potencialidades desenvolvidas na consolidação do conceito de patrimônio.

\section{O trabalho na sala de aula}

Conforme já foi destacado, a ideia de trabalharmos com o conceito de patrimônio surgiu a partir da necessidade de desenvolver com os alunos a identificação, o reconhecimento e a valorização em relação ao patrimônio local, seja ele material ou imaterial. O ponto de partida do nosso planejamento era possibilitar a compreensão de que a educação para o patrimônio é um instrumento de conscientização para a valorização da história local e regional, na medida em que o sujeito se apropria do conceito e consegue mobilizá-lo em outras situações, como nas ações cotidianas portadoras de importância sociocultural.

Iniciamos nosso planejamento fazendo referência à etapa (i) do projeto Imaginando, discussão teórica sobre o conteúdo e conceito, apresentando um vídeo com diversas imagens de patrimônios do Estado do Espírito Santo captadas da internet, como também contendo um breve panorama da história do município de Serra ${ }^{4}$. Após o vídeo realizamos uma dinâmica chamada "tempestade de ideias", que consistia em questionar os alunos a respeito do conceito de patrimônio. O questionamento inicial foi: "Na opinião de cada um de vocês, o que significa 'patrimônio'?" Montamos um quadro com todas as palavras ditas representadas a seguir: a palavra "construções" apareceu 15 vezes; a palavra "praia" 5 vezes; a palavra "praça" apareceu 3 vezes; a palavra "shopping" 3 vezes e a palavra "igrejas" apareceu quatro vezes.

Os vídeos e imagens utilizadas no desenvolvimento de todas as atividades podem ser acessados em: http:// olharesdeumacidade.blogspot.com 
As palavras supradescritas foram mediadas pelas informações do vídeo apresentado aos alunos quando iniciamos nossa atividade. Acreditamos que muitas delas foram apreendidas em consequência das imagens que selecionamos para nossa apresentação. Grande parte deles, entretanto, não soube explicar como a palavra dita representava patrimônio, pois nunca haviam ouvido essa palavra. Eles diziam: "Eu nunca ouvi essa palavra 'patrimônio'!" Mesmo sem uma aprendizagem deliberada, 99\% das palavras registradas durante a dinâmica tinham relação com o patrimônio edificado, valorizando apenas as questões materiais do patrimônio.

A necessidade em trabalharmos com as temáticas de patrimônio material e imaterial são visíveis para a ampliação da potencialidade das abordagens de bens culturais mais próximos das realidades dos alunos. As noções de patrimônio foram expandidas após a aula expositiva e se inter-relacionaram aos sentidos do grupo por meio dos valores simbólicos já construídos. Por exemplo, ouvimos falas de alguns alunos, como: "Então professora, podemos dizer que a cultura das pessoas também é patrimônio?"; "O quadro da minha avó que fica na parede da sala da minha casa é um patrimônio da minha família!"; "Professora, a dança do congo é um patrimônio imaterial da Serra?"

Quando paramos para analisar essas falas, percebemos que o estabelecimento da relação entre o bem patrimonial e as vivências reconhecidas nele pelos indivíduos ou grupo sociais é o fundamento mais importante na construção da identidade coletiva. O que buscamos com essa atividade de exposição do conceito e a produção fotográfica que o represente é permitir o exercício da pesquisa, "[...] das realidades vividas pelos sujeitos e a consequente enunciação de valores, bens e saberes patrimonializáveis para uma comunidade" (LACERDA et al., 2015, p. 29). A intenção principal é despertar para além do conhecimento e representação do conceito, processos reais de registro e preservação, fazendo com que a problemática do patrimônio não seja vivida como algo externo aos sujeitos que vivem o processo cultural, mas como parte de sua vida em curso.

Quando, entretanto, numa atividade perguntamos o significado de "patrimônio", recebemos as seguintes respostas.

Imagem 1 - Gráfico explicativo dos significados de patrimônio

\title{
Significados de Patrimônio dos alunos
}

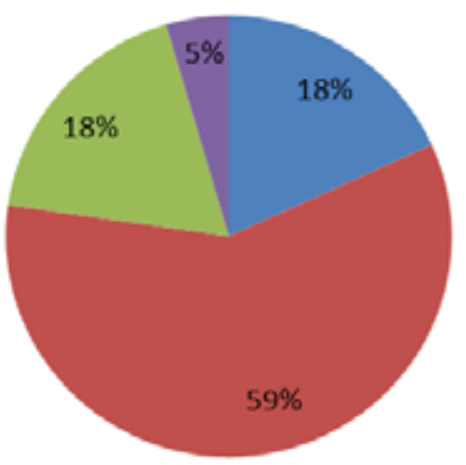

\author{
- Patrimônio Imaterial (modos de \\ viver, festas e danças) \\ - Patrimônio \\ Arquitetônico/material (igrejas, \\ praças, estátuas) \\ " Tempo histórico ( questões \\ relacionadas ao passado) \\ Eatrimônio Cultural
}


No decorrer da aula expositiva, que, conforme a organização do trabalho, ocorreu na primeira etapa do projeto Imaginando, percebemos a necessidade de focalizarmos o caráter intersubjetivo, sensível, multidirecional e relacional do patrimônio. Compreendemos que a noção estreita que compõe o entendimento de grande parte dos alunos está relacionada a construções, como edificações e organização do espaço urbano. Em número menor, mas para nós significativo, $18 \%$ dos alunos relacionaram o patrimônio às práticas sociais e às diversas manifestações artísticas e culturais.

Curiosamente um dado nos surpreendeu, pois $18 \%$ dos alunos associou o conceito de tempo histórico reconhecendo elementos e objetos do passado como algo do universo patrimonial. Somente $5 \%$ dos alunos abordou em sua resposta uma percepção de patrimônio cultural mais ampliada, permitindo, além de questões materiais, a admissão de bens culturais a serem patrimonializados, como práticas, lugares, celebrações, dentre outros.

Como vemos, projetos educativos, caracterizados por dimensões subjetivas e sociais, são imprescindíveis no processo de democratização das noções de cultura e patrimônio. "Esta nova face do patrimônio repercute também nas ações educativas desenvolvidas que transitam referências culturais [...] democratizando o direito à memória em diferentes escalas [...]" (LACERDA et al., 2015, p. 27). Como último exercício foi proposto que alunos escrevessem quais atitudes poderíamos ter para preservarmos o patrimônio cultural de nossa cidade. Constatamos que $100 \%$ dos alunos fizeram referência ao local correto de jogar o lixo para não poluirmos os lugares, como também citaram questões relacionadas ao vandalismo que destrói locais de memória, como igrejas, teatros, praças e estátuas.

Seguindo nosso planejamento propomos como tarefa a produção fotográfica para representar o conceito de patrimônio discutido durante a aula. Explicamos aos alunos que para a etapa (ii) de desenvolvimento da metodologia Imaginando faríamos uma aula de campo no Sítio Histórico da Serra Sede ${ }^{5}$. Selecionamos alguns lugares, tendo em vista a importância dentro da história de Serra e sua significação para a comunidade serrana. Foram escolhidos o Museu Histórico da Serra, a Casa do Congo, a Igreja de Nossa Senhora da Conceição, a praça central de Serra-Sede e a famosa estátua do escravo Chico Prego ${ }^{6}$. Dentro da nossa programação estavam incluídas uma visita guiada ao Museu, uma palestra sobre a história a respeito da construção da estátua do Chico Prego e uma apresentação do ritmo do congo (essas duas últimas atividades aconteceram dentro da Casa do Congo).

A proposta pela aula com visitas orientadas foi pensada por dois motivos importantes: primeiro para permitir que os alunos tivessem contato com o patrimônio cultural tão importante para o reconhecimento da identidade da comunidade local, uma vez

\footnotetext{
É o centro histórico mais antigo do município, que começou junto com sua colonização. Fomentado pela presença da Prefeitura, Câmara de Vereadores, Fórum, bancos públicos e privados além de oito escolas que atendem a moradores de bairros vizinhos, estima-se que mais de 15 mil pessoas circulem diariamente no comércio local. Disponível em: http://www.serra.es.gov.br. Acesso em: 9 jan. 2018.

6 Chico Prego foi um escravo líder da revolução em Queimado, morto por enforcamento na Vila de Nossa Senhora da Conceição da Serra no dia 11 de janeiro de 1850. A estátua, construída com recurso da lei Chico Prego, concebida e executada pelo artesão Jacob Kuster (Tute), pesa 4 toneladas e está próxima ao local da execução de Chico Prego há mais de 150 anos. Para saber mais, ver em: BORGES, Clério José. História da Serra. Serra: Editora CTC, 2009.
} 
que muitos não conheciam o centro histórico Serra-Sede e nem o centro administrativo. O outro motivo que nos levou a realizar essa visita correspondia com a ideia de promover um momento de mediação para a produção da fotografia.

No nosso segundo encontro realizamos uma visita orientada ao centro histórico da Serra-Sede. Foi um momento rico em experiências, trocas e construção do conhecimento da história local. A visita aos locais de memória da comunidade serrana proporcionou uma valiosa experiência histórica construída em todos os pontos visitados. Os alunos puderam fotografar durante todo o percurso, e tinham a tarefa de escolher somente uma fotografia para apresentar e compartilhar seus significados em nosso próximo encontro. Realizamos nossa aula-passeio no turno matutino durante o período da aula, com agendamento prévio em todos os locais visitados.

As fotografias produzidas na visita foram focalizadas no terceiro encontro, e o retornou foi surpreendente, pois as fotografias e os significados apreendidos pelos alunos foram além de nossas expectativas. Assim que chegamos uma aluna nos abordou ainda na porta da sala e declarou: "Professora, eu levei a minha família no final de semana para conhecer a Serra-Sede e meu pai achou incrível. Ninguém na minha casa conhecia e eu levei eles em todos os lugares que a gente foi!" Com essa recepção o nosso terceiro encontro não poderia ter começado melhor.

Dando continuidade ao nosso momento de consolidação coletiva das imagens-conceito, cada um dos alunos apresentou a foto selecionada para representar o patrimônio. Para essa atividade utilizamos recursos como computador e datashow dentre outros. Resgatamos as fotografias dos aparelhos eletrônicos dos alunos e apresentamos para toda a turma, momento em que todos puderam apreciar as imagens uns dos outros.

Foram 22 imagens selecionadas. Dessas, 7 fotografias estavam relacionadas ao patrimônio arquitetônico e todas foram registradas dentro da Igreja e em seu entorno. Outras 4 referem-se a instrumentos do congo e elementos culturais, como pinturas e esculturas produzidas pela comunidade (essas foram registradas dentro da Casa do Congo, conforme identificação da ficha descritiva). Apenas um aluno registrou uma imagem fazendo referência ao patrimônio imaterial. Essa foto foi produzida durante a apresentação musical dentro da Casa do Congo. Grande parte dos alunos (ou seja, 45\% deles = 10 alunos), para representar o conceito de patrimônio, utilizou a figura da estátua de Chico Prego. Quando questionados sobre o que os motivou para tal registro, todos foram enfáticos ao firmar que gostaram muito da palestra com a explicação e história da vida desse escravo tão importante para a cidade de Serra.

Durante todo o processo de consolidação do conceito constatamos que pesquisas como a nossa, dentro da escola, em particular no ensino de história, eram fundamentais no fortalecimento da identidade local. A escola apresenta-se com o locus privilegiado para o exercício e questionamento do sentido histórico atribuído ao patrimônio.

Entender as relações indispensáveis da modernidade com o passado requer examinar as operações de ritualização cultural. Para que as tradições sirvam hoje de legitimação para aqueles que as construíram ou se apropriam delas, é necessário colocá-las em cena. O patrimônio existe como força política na medida em que é teatralizado: em comemorações, monumentos e museus (CANCLINI, 2008, p. 161-162). 
Quando socializamos o conhecimento historicamente produzido e preparamos as atuais e futuras gerações para a construção de novos conhecimentos, devemos ter como ponto de partida questionamentos a respeito da identidade e memória evocadas pela sociedade. Concordamos que "[...] é necessário questionar essa hipótese central do tradicionalismo segundo a qual a identidade cultural se apóia em um patrimônio, constituído através de dois movimentos: a ocupação de um território e a formação de coleções" (CANCLINI, 2008, p. 190). Dessa forma evitaremos que o patrimônio sirva de lugar para testemunhos da dominação, reflexões que nos fazem recordar a frase de Benjamin (2012), quando ensina que todo documento de cultura é, sempre, de alguma forma, um documento de barbárie.

Selecionamos a Imagem 2 para analisarmos a consolidação do conceito de patrimônio, por representar a escolha de $45 \%$ dos alunos. Como dito anteriormente, grande parte deles associou o conceito à estátua do escravo Chico Prego.

Imagem 2 - Fotografia produzida para representar o conceito de "patrimônio"

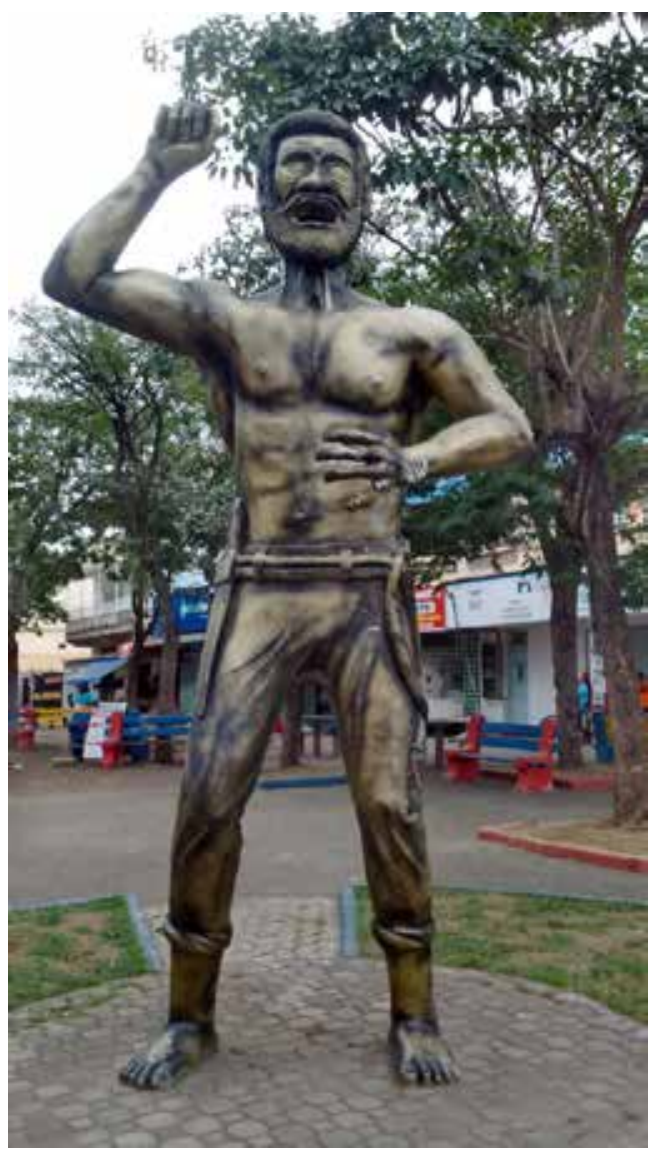

Fonte: MALVERDES (2018, p. 154). 
Imagem 3 - Fragmento da ficha descritiva da Imagem 2

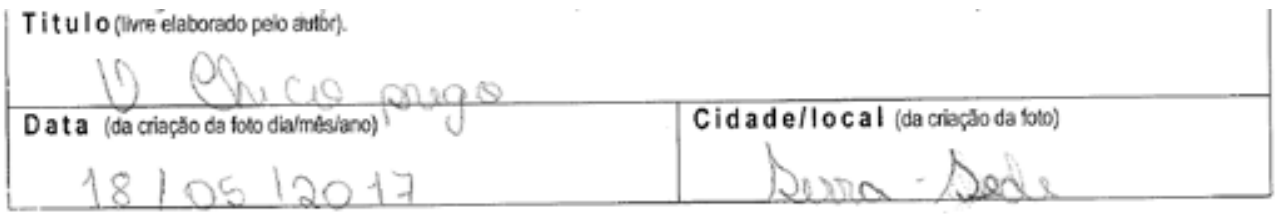

DESCRIÇÃO DO CONTEÚDO

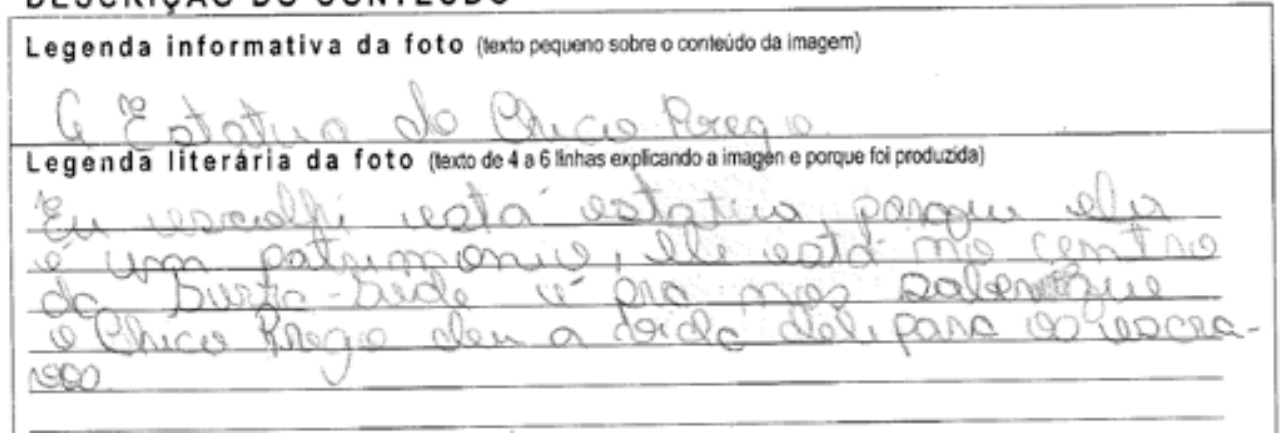

Fonte: MALVERDES (2018, p. 156).

A Imagem 2 foi escolhida pela aluna para representar o conceito de patrimônio. A partir da análise da ficha descritiva (Imagem 3), etapa (v) da metodologia, percebemos que sua escolha buscou critérios objetivos e intersubjetivos para a significação dada. Na legenda informativa da foto ela explica: "Eu escolhi esta estátua porque [...] o Chico Prego deu a vida dele para os escravos". Percebemos que o valor determinado dos objetos não está inserido nele próprio, mas possui significados que são conferidos pelos indivíduos e grupos ao longo de suas vivências e experiências. Cabe ressaltar que a etapa (iv) da metodologia, que se refere ao ajuste da imagem, não foi necessário durante o processo de nosso estudo e pesquisa.

Como observou Kossoy (2012, p. 47), "toda fotografia tem atrás de si uma história". Quando olhamos para uma fotografia precisamos perceber nela o reflexo da sua trajetória e situá-la em três estágios que permitem a decifração de seus significados. São eles: a intenção para que ela existisse; 0 ato do registro que materializou a fotografia; e, por fim, os caminhos percorridos pela imagem bem como a representação e significação apreendidas. A perspectiva do nosso trabalho com a fotografia defende 0 seu uso na qualidade de fonte histórica. Caracteriza-se como um artefato que nos oferece indícios dos elementos constitutivos (assunto e fotógrafo), como também reúne um inventário de informações acerca do fragmento de tempo/espaço. Mediante a materialização desses materiais e técnicas constitui-se uma fonte histórica.

A relevante contribuição que Vygotsky (2005) desenvolve no processo de significações culturais fornecidas por determinado grupo social, traz para nossa pesquisa um novo olhar para a relação do sujeito com o mundo. Pensar o conceito de patrimônio na escola, dentro da perspectiva do autor, portanto, significa pensar na construção desse conceito a partir das relações dos sujeitos com determinados bens culturais. As possibilidades de múltiplas significações atribuídas à imagem (ver Imagem 1), a partir da sua interpretação durante o grupo de discussão, chamou-nos a atenção para essa análise. 
A reflexão sobre o conceito de patrimônio, na perspectiva cultural de Vygotsky (2005), nos faz compreender e reconhecer outros sentidos para o patrimônio que vão muito além do seu significado tradicional, posto que ampliamos os contextos sociais e as diversas possibilidades de experiência e mediação. "Essa nova acepção requer [...] modificações na noção de autenticidade do patrimônio que incorporem a mutabilidade cultural própria à pluralidade da experiência que marca o patrimônio imaterial [...]" (LACERDA et al., 2015, p. 30).

Para desenvolvermos a arqueologia da imagem (CIAVATTA, 2002), a interpretação da fotografia deve se valer também da intertextualidade e seu sentido social como produto cultural. Concluímos, por meio da análise da legenda da ficha descritiva (Imagem 3), que "[...] a fotografia, como todas as linguagens, não se esgota na ação do fotógrafo, ela estabelece um diálogo com o leitor, que faz a sua leitura sobre aquilo que vê" (CIAVATTA, 2002, p. 48).

Ao tomarmos os aspectos que constituem a fotografia e entendermos o processo da sua criação/representação, percebemos que no caminho percorrido a aluna definiu os processos de criação elencando um local, um espaço específico e o melhor ângulo para enquadramento e captação da fotografia. Elaborou-se também todo um esquema de significação para representar o patrimônio, e, com o auxílio da ficha descritiva, registrou-se suas perspectivas ao apresentar a foto-conceito para o grupo. Constatamos que o caminho percorrido para a descrição da fotografia apresenta todo o conjunto de elementos necessários para a interpretação iconográfica e iconológica proposta por Kossoy (2007).

\section{CONCLUSÕES E CAMINHOS POSSÍVEIS}

Então? Interesse? Isso é insuficiente; não tenho necessidade de interrogar minha comoção para enumerar as diferentes razões que temos para nos interessarmos por uma foto; podemos: seja desejar o objeto, a paisagem, o corpo que ela representa; [...] seja admirar ou discutir o desempenho do fotógrafo. Etc.; [...] Assim, parecia-me que a palavra mais adequada para designar (provisoriamente) a atração que sobre mim exercem certas fotos era aventura (BARTHES, 1984).

O princípio da aventura, descrito por Barthes, foi o fio condutor que direcionou e alimentou o nosso trabalho ao longo deste estudo. Desenvolver e apresentar para o cenário do ensino de história nos anos iniciais do Ensino Fundamental uma possibilidade original e significativa de aprendizagem, foi verdadeiramente uma "aventura". Quando pensamos em ensinar história para crianças alguns desafios são colocados em nosso caminho, entretanto nossas reflexões nos permitem afirmar que jamais devemos deixar de possibilitar a esse ensino um caráter transformador, despertando a percepção de que a história é construção humana.

A proposta para desenvolver diferentes estratégias metodológicas ao longo de nossa pesquisa, em particular com o uso da fotografia, nos fez refletir sobre as contribuições desse documento imagético como fonte histórica escolar no ensino de história. 
Como ponto de partida buscamos compreender o cenário de constituição e desenvolvimento da disciplina de história nos anos iniciais do Ensino Fundamental. Compreendemos, com base no estudo e reflexões de autores, como Fonseca (2006) e Bittencourt (2011), que pesquisas dedicadas à história do ensino de história não se apresentam muito no cenário acadêmico brasileiro.

Outro fator analisado por nossa pesquisa em relação à aprendizagem histórica, compreende o ensinar e aprender história utilizando fontes diversas. Ancorados por Bloch (2001, p. 79), acreditamos que "A diversidade dos testemunhos históricos é quase infinita". Com efeito, trata-se, portanto, de analisar a relação bilateral entre o conhecimento histórico e a forma na qual o trabalho com as fontes contribui na formação da consciência histórica dos alunos. A partir desses elementos o trabalho com as fontes assume uma dimensão e um caráter transformador na relação de ensino.

O desenvolvimento da aprendizagem de conceitos teve como suporte metodológico a metodologia Imaginando. Durante sua aplicação, percebemos que a aprendizagem se torna significativa para os alunos quando os mesmos são inseridos no processo, mas não como espectadores e, sim, como sujeitos construtores do conhecimento. A participação efetiva em todas as etapas da metodologia foi a grande motivação impulsionadora das experiências vivenciadas e compartilhadas.

Como afirma Barthes (1984, p. 57), "Em um primeiro tempo, a Fotografia, para surpreender, fotografa o notável; mas logo, por uma inversão conhecida, ela decreta notável aquilo que ela fotografa. O 'não importa o quê' se torna o ponto mais sofisticado do valor". Por meio dos elementos constituintes na cena fotográfica, nas disposições e no espaço, foi possível compreender a história de cada registro produzido pelos alunos, bem como possibilitou o entendimento dos significados atribuídos em cada fotografia.

A ideia de desenvolver o conceito de patrimônio como algo presente nas coletividades e na própria vida dos alunos permite o protagonismo nas atividades de investigação no espaço da sala de aula e em seu entorno. A utilização da fotografia nesse contexto ajuda na organização e na compreensão dos conteúdos por apresentar uma função comunicativa de transmitir as mensagens mais explícitas em diferentes perspectivas. Como afirma Sontag (2004, p. 191),

A fotografia não apenas reproduz o real, recicla-o - um procedimento fundamental numa sociedade moderna. Na forma de imagens fotográficas, coisas e fatos recebem novos usos, destinados a novos significados, que ultrapassam as distinções entre o belo e o feio, o verdadeiro e o falso, o útil e o inútil, bom gosto e mau gosto. A fotografia é um dos principais meios de produzir esse atributo, conferido às coisas e às situações, que apaga aquelas distinções: "o interessante". O que torna uma coisa interessante é que ela pode ser vista como parecida, ou análoga, a outra coisa.

Assim, a partir do trabalho de pesquisa com os alunos, percebemos como é significativo e possível desenvolver capacidades e habilidades por meio da alfabetização visual. Foi possível constatar o quanto o processo de aprendizagem e a apreensão dos conteúdos foram facilitados mediante a linguagem fotográfica. Acreditamos, dessa forma, na noção de que a fotografia não reproduz apenas o real, mas lhe dá uma nova significação; ressignifica o objeto focalizado, no caso o patrimônio. Essa linguagem, no ensino, é um potente instrumento de construção dos conceitos. 


\section{REFERÊNCIAS}

BARTHES, Roland. A câmara clara: notas sobre a fotografia. Rio de Janeiro: Nova Fronteira, 1984.

BENJAMIN, Walter. Magia e técnica, arte e política: ensaios sobre literatura e história da cultura. 8. ed. Revista (Obras Escolhidas, v. 1). São Paulo: Brasiliense, 2012.

BITTENCOURT, Circe Maria Fernandes. (Org.). O saber histórico na sala de aula. 12. ed. São Paulo: Contexto, 2015.

BITTENCOURT, Circe Maria Fernandes. Ensino de história: fundamentos e métodos. 4. ed. São Paulo: Cortez Editora, 2011.

BLOCH, Marc. Apologia da história ou o ofício do historiador. Rio de Janeiro: Jorge Zahar Editor, 2001.

BRASIL. Constituição da República Federativa do Brasil. Brasília. DF: Senado Federal, 1988.

BRASIL. Lei no 3.551, de 4 de agosto de 2000. Disponível em: http://www.planalto.gov.br/ccivil_03/decreto/d3551.htm Acesso em: 20 fev. 2017.

CAIMI, Flávia Eloisa. Conversas e controvérsias: o ensino de história do Brasil (1980-1998). Passo Fundo: UFP, 2001.

CANCLINI, Néstor Garcia. Culturas híbridas. São Paulo: Edusp, 2008.

CIAVATTA, Maria. O mundo do trabalho em imagens: a fotografia como fonte histórica. Rio de Janeiro: DP\&A, 2002.

COOPER, Hilary. Aprendendo e ensinando sobre o passado a crianças de três a oito anos. Dossiê: Educação Histórica. Educar em Revista, Curitiba, n. especial, p. 171-190, 2006. Disponível em: http://revistas. ufpr.br/educar/issue/view/251/showToc. Acesso em: 15 abr. 2017.

COOPER, Hilary. Ensino de história na educação infantil e anos iniciais: um guia para professores. Curitiba: Base Editorial, 2012.

CHARTIER, Roger. A história cultural entre práticas e representações. Tradução Maria Manuela Galhardo. Lisboa: Difusão Editorial, 2002.

FONSECA, Thais Nívia de Lima e. História \& ensino de história. 2. ed. Belo Horizonte: Ed. Autêntica, 2006. KOSSOY, Boris. Fotografia \& história. 4. ed. São Paulo: Ateliê Editorial, 2012.

KOSSOY, Boris. Os tempos da fotografia: o efêmero e o perpétuo. São Paulo: Ateliê Editorial, 2007.

LACERDA, Aroldo Dias et al. Patrimônio cultural em oficinas: atividades em contextos escolares. 1. ed. Belo Horizonte, MG: Fino Traço, 2015.

LOPEZ, André Porto Ancona et al. Imaginando: imagens-conceito de termos arquivísticos. Revista do Colóquio, v. 3, n. 5, p. 203-213, dez. 2013. ISSN 2358-3169. Disponível em: http://periodicos.ufes.br/colartes/ article/view/7696. Acesso em: 15 maio 2017.

MALVERDES, C. Z. Fotografia e ensino: uso e aplicação da fotografia no processo de aprendizagem no ensino de história e educação patrimonial. 2018. Dissertação (Mestrado em Ensino na Educação Básica) - Universidade Federal do Espírito Santo, Centro Universitário Norte do Espírito Santo, São Mateus, 2018. NORA, P. Mémoire collective. In: LE GOFF, Jacques (curatore). La nouvelle histoire. Paris: Retz, 1978.

OLIVEIRA, Sandra Regina Ferreira de. Os tempos que a história tem... In: COLEÇÃO EXPLORANDO O ENSINO. História. Volume 21, Ensino Fundamental. Brasília: MEC, 2010.

ORIÁ, R. Memória e ensino de história. In: BITTENCOURT, Circe (org.). O saber histórico na sala de aula. 12. ed. São Paulo: Contexto, 2015.

PAIM, Elison Antonio. Lembrando, eu existo. COLEÇÃO EXPLORANDO O ENSINO. História. Volume 21, Ensino Fundamental: Brasília: MEC, 2010.

REGO, Teresa Cristina. Vygotsky: uma perspectiva histórico-cultural da educação. Petrópolis: Vozes, 1995. SONTAG, Susan. Sobre fotografia. Trad. Rubens Figueiredo. São Paulo, SP: Companhia das Letras, 2004.

VIGIL, J. (ed.). Imaginando: uso y aplicación de la fotografía en los procesos de aprendizaje. Madri: Universidad Complutense de Madrid, 2012. Disponível em: http://apalopez.info/GPAF/IMAGINANDO_texto_color.pdf. Acesso em: 14 nov. 2016.

VYGOTSKY, L. S. Pensamento e linguagem. 3. ed. São Paulo: Martins Fontes, 2005. 